\title{
Contando e compartilhando narrativas acadêmicas sobre a boa comunicação*
}

Giovanni Bechelloni

Professor de Sociologia da Comunicação na Universidade La Sapienza de Roma e membro do CSS - Italian Council for Social Sciences.

E-mail: g.bechelloni@mclink.it

Resumo: $\bigcirc$ artigo fala dos desafios trazidos pela sociedade fragmentada de hoje, estruturada em decorrência de processos sociais desenvolvidos a partir da Segunda Guerra, e sobre o papel da comunicação dentro desta sociedade. Trata ainda das diversas fases da modernidade e de como as sociedades - em especial as mediterrâneas - devem buscar sua identidade para se posicionar no mundo contemporâneo.

Palavras-chave: Comunicação, história, modernidade, Segunda Guerra, Mediterrâneo.
Abstract: This article approaches the challenges brought by today's fragmented society, structured as a result of social processes developed from the Second World War, and the role of communication within this society. It approaches the several stages of modernity and how societies -specially the Mediterranean ones - should seek for their identity to face the world in which we live in.

Keywords: Communication, history, modernity, second world war, Mediterranean societies.

\section{PRECISAMOS DE BOA COMUNICAÇÃO}

Estamos em um momento decisivo. Não acredito que seja o "fim da história" (Hegel-Fukuyama) nem o "fim do mundo". Talvez a palavra Apocalipse seja mais próxima da realidade, significando: os desastres estão aqui - como a grande crise econômico-financeira de 2008, ou como a ideia de sociedade fragmentada sobre a qual Philip Blond escreve -, em um movimento que busca superar tanto o "individualismo egocêntrico" quanto as decisões financeiro-econômicas e políticas excessivamente centralizadas (em uma "desregulamentação") em direção ao novo comunitarismo.

Acredito que, quando a situação parece ser a pior, ainda assim podemos encontrar uma boa saída. Podemos - como acadêmicos da área - contribuir para resgatar a comunicação. Minha questão é: o uso equivocado da palavra comunicação está colocando em risco a existência dos seres humanos como são?

Se a resposta for sim, temos um grande problema. Convencido de que a má comunicação é regra e a boa comunicação, rara, comecei a trabalhar em um "livro-manifesto" que pode se chamar "A boa comunicação e seus inimigos",

* Palestra de abertura do Seminário Internacional Novos Caminhos para os Estudos e Estratégias de Comunicações. Legados e Desafios; Temores e Esperanças (Siena, Itália, de 10 a 3 de junho de 2010). 
comunicação \& educação • Ano XVII • número 1 • jan/jun 2012

"A boa comunicação e seus amigos" ou "Boa comunicação para um mundo melhor". "Boa" e "má" porque a palavra comunicação não é mais usada como era antes: humanos encontram outros a fim de gerar comunidades, história... e outros não significa estranhos. Pelo contrário: são irmãos, pais, filhos e mesmo o outro que existe dentro de nós.

Nos Estados Unidos, existem bons exemplos de comunicação, como The New York Times e The Peabody Awards (pela excelência em mídia eletrônica). Porém, nos últimos anos, o país retrocedeu até ser considerado "a Nação Perigosa" - por causa de Bush e do Iraque, mas, principalmente, conforme Dan Shiller escreveu no Le Monde Diplomatique, por ser lar do modelo capitalista criado pelo negócio financeiro e pela mídia digital, além de toda a "comunicação" enganosa (propaganda) que convence os mais jovens de um futuro maravilhoso sem livros, jornais, televisão, sem aprender com os mestres

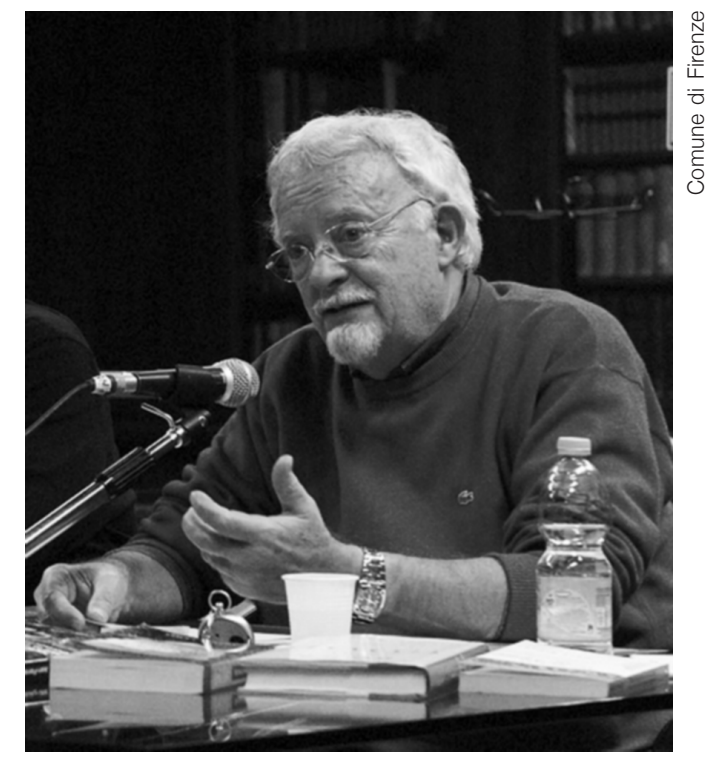

Prof. Giovanni Bechelloni. o uso das palavras e assim por diante.

Mas ainda penso que ESPERANÇAS são mais poderosas do que MEDOS. Deveríamos entender o que está errado na comunicação e na forma como usamos suas tecnologias e instituições:

- dos meios "tradicionais" para os meios digitais;

- das aulas escolares para as universidades.

Devemos explorar melhor o que podemos fazer com a Alfabetização Midiática, a Alfabetização em Comunicação, a Alfabetização Religiosa e a Alfabetização Cívica, tendo em mente novas ideias sobre ignorância e conhecimento. Os significados de ambas não são parte de disciplinas ou ciências, mas relacionados ao que era chamado por Sócrates ou Maquiavel de "as coisas do mundo". É o conhecimento constituído por "histórias" que passam de uma geração a outra, adquirido no contexto da experiência e não na escola. Hoje em dia, ele vem às pessoas a partir dos meios de comunicação e da sociedade de consumo, sem mediação de humanos ou de instituições de ensino.

Isso acontece em escala maior do que antigamente: mesmo entre pessoas que possuem ensino superior, e que expressam opiniões efetivas na sociedade democrática, há a ignorância enganadora sobre "as coisas do mundo". Poucas estão conscientes de que hoje, em que mesmo a distinção entre guerra e paz ou criminoso e não criminoso é difícil de perceber, as coisas do mundo são dramaticamente mais complexas - e de que, em muitos casos, as decisões são tomadas sem o suporte do conhecimento a partir de opiniões criadas pela má informação. Assim, as instituições democráticas trabalham numa condição fraca e as lideranças confiáveis têm dificuldades para emergir. 


\section{Contando e compartilhando narrativas acadêmicas - Giovanni Bechelloni}

Então nós, acadêmicos, poderíamos ser ativos em construir o conhecimento necessário à boa comunicação. Deveríamos voltar ao ensaio de Adorno-Horkheimer sobre a indústria cultural, adicionando o que aprendemos durante as revoluções culturais e da comunicação de 1960 e 1970 (contra a sociedade e o "sistema") e daquelas dos anos de 1980 e 1990 (a favor do livre mercado e da privatização e contra o Estado e os políticos).

Sugiro uma narrativa que encontra no passado ideias ainda úteis hoje: o Legado Mediterrâneo e Legado de Maquiavel em direção a um cosmopolitismo responsável ${ }^{1}$.

\section{A PRIMEIRA MODERNIDADE}

Chegou a hora de pensar "A Mente Mediterrânea" como uma alternativa à forma dominante de globalização e de "sociedade da informação". A Mente Mediterrânea é uma nova ideia com raízes antigas. Conecta pessoas que têm em comum lugares e culturas ocidentais ou orientais, setentrionais ou meridionais, componentes da humana civilitas (civilização humana).

Desde o fim da Segunda Guerra Mundial, muitas coisas mudaram e ainda não estamos conscientes das consequências dessas mudanças para o futuro. Não podemos construir um mundo melhor se não pensarmos no passado, a fim de modificar nossa percepção da modernidade - que tem raízes no que chamo de "primeira modernidade".

A primeira modernidade, ainda presente em algumas culturas, tem início na Roma mediterrânea de Cícero e na China Asiática de Sun Tzu. Em ambas, os significados das coisas do mundo são estritamente conectados a contextos. A segunda modernidade nasceu depois, nas regiões setentrionais da Europa, conectada às culturas alemã e escandinava, à Reforma e às culturas do livro e do indivíduo.

A História é, em muitos casos, escrita pelos vencedores, enquanto a memória coletiva não é construída por historiadores, mas pela comunicação intergeracional. Dessa forma, as coisas podem mudar seus nomes enquanto mantêm seus significados. Como consequência, o conhecimento público sobre o passado pode ser manipulado, gerando a ideia de que "pensar sobre o passado é um obstáculo para a construção do futuro".

Portanto, ao invés do conhecimento real, aceitamos os estereótipos e o otimismo exagerado. A ideia de multiculturalismo é consequência desta maneira de pensar. O mesmo acontece com outros conceitos relacionadas a globalização, capitalismo, democracia, modernidade, choque de civilizações...

Minha hipótese é de que temos que redirecionar nossa identidade em direção ao que K. A. Appiah ${ }^{2}$ entende por cosmopolitismo. Minha pesquisa foi iniciada a partir da ideia de ver o passado com o olhar da comunicação, com a sensibilidade dos que o viveram, a consciência do tempo presente e a necessidade de construir um futuro melhor, a fim de entender e encontrar o Outro.
1. APPIAH, Kwame Anthony. Cosmopolitanism Ethics in a World of Strangers [Cosmopolitismo. Ética num Mundo de Desconhecidos]. New York: Norton, 2006 BECHELLONI, Giovanni. Diventare cittadini del mondo [Tornar-se cidadão do mundo]. Roma-Firenze: Mediascape 2006.

2. APPIAH Kwame Anthony. Cosmopolitanism Ethics in a World of Strangers, cit. 
comunicação \& educação • Ano XVII • número 1 • jan/jun 2012

Migrações e hibridizações foram as principais forças no sentido de criar uma civilização (na concepção de Braudel) na China Antiga e no Mediterrâneo. Essas foram, desde o princípio, "sociedades abertas". Quando a agricultura foi inventada e as cidades começaram a crescer, ao lado da escrita e da divisão do trabalho, as sociedades complexas surgiram. Mais tarde, quando Roma, com as contribuições dos etruscos, gregos e dos que vieram do oriente e do sul, passou a centralizar o novo mundo, a modernidade começou a existir. Ao lado de Atenas e Jerusalém, formou o berço da modernidade que cresceu com Constantinopla, Rússia, as cidades italianas, o Sacro Império Alemão e os Impérios Português e Espanhol.

Mas a palavra modernidade não foi inventada para descrever o que a existência dos humanos construiu. Minha ideia - que não é apenas minha - é de que deveríamos dar o nome de primeira modernidade a este período no qual se inventaram muitas das coisas que ainda são parte importante de nossa vida.

\section{O LEGADO MEDITERRÂNEO}

O papel social dos territórios mudou dramaticamente. Não apenas se pode viajar de forma mais fácil e barata, mas é possível construir identidades com múltiplos sensos de pertencimento: viajando e, ao mesmo tempo, ansiando por uma pátria. A geopolítica tornou-se novamente importante, assim como a geocultura ou a geocomunicação. Essas mudanças trouxeram novas oportunidades para a multipolaridade e para territórios antes condenados à marginalidade. É num contexto geral de consequências inesperadas que o olhar mediterrâneo está de volta.

Pensar, para as mentes mediterrâneas, significa abrir olhos e ouvidos através do tempo e do espaço para culturas que chegaram há três mil anos, assim como para cinco ou seis grupos linguísticos e geoculturais que criaram o modo de pensar que nós, sociólogos comparativos, identificamos com o "mediterrâneo" além dos povos que, por meio de migrações, se encontraram em outros países do mundo: na América Latina, na Ásia e África, Austrália e Canadá, Estados Unidos e Europa setentrional.

Em certo sentido, todo o mundo está interessado nos significados ligados ao olhar mediterrâneo. O centro está, obviamente, no geoespaço que inclui a Europa meridional, os Bálcãs e os países do MENA (Oriente Médio e África setentrional).

Desde o fim da Segunda Guerra Mundial, muitos se conscientizaram da

3. GIRARD, René. Achever Clausewitz [Clausewitz Completo]. Paris: Carnets Nord, 2008.

4. DELPECH, Thérèse. L'ensauvagement. Le retour de la barbarie au $\mathrm{XXI}$ siècle [A selvageria. O retorno da barbárie no século $X X I]$. Paris: Hachette, 2005. possibilidade da extinção da vida humana. Não apenas pela "invenção" das armas de destruição em massa, mas também pelo aumento da inabilidade dos humanos de se regular (a partir da bem conhecida tese do sociólogo Norbert Elias em Humana conditio).

Depois do fim da Guerra Fria e do colapso do comunismo, "teorias" enganosas começaram a circular - da teoria otimista do "fim da história" de Fukuyama à teoria pessimista do "choque de civilizações" de Huntington. Alguns sugeriram a necessidade de reação ${ }^{3}$ ao risco ${ }^{4}$ de o Mundo Ocidental voltar ao pensamento 
"bárbaro" (antes da invenção da cultura e da comunicação); outros sugeriram à Europa o "estilo romano", enquanto outros se dividiram entre unilateralistas vs multilateralistas, ou neoconservadores vs neorrealistas no modo de enfrentar a chamada "guerra ao terrorismo", considerada por alguns como a "IV Guerra Mundial" e, por outros, como nem mesmo uma guerra - sendo "o terrorista" uma nova encarnação de "o partisan" .

O ponto de partida pode ser uma nova ideia sobre a "mente mediterrânea" a partir da sociologia de Pierre Bourdieu no último período de sua vida: não apenas "um esporte de combate", mas também uma "nova ciência unificada", apta a manter juntas não apenas as ciências sociais e as humanidades, mas também as ciências físicas e biológicas - uma "nova ciência" próxima às ideias do filósofo Giambattista Vico, quando postulou, em oposição a Descartes, a "scienza nova".

Assim, é importante pensar sobre: 1) o conceito aberto de mediterrâneo cultivado por pessoas como Albert Camus (Judt 2005 e 2007); 2) a abordagem da "long durée" à história da humana civilitas, colocando de lado ideias como ocidental e oriental e repensando a modernidade e a secularização; 3) o novo conceito de territorialidade, construído com a ajuda da abordagem geossociológica para as mudanças na geopolítica e nas relações internacionais.

Podemos então trabalhar sobre algumas hipóteses - entre elas, a afirmação de que o mundo mediterrâneo não foi o berço da civilização ocidental, mas ponto de hibridização de grupos de diversos lugares, construindo uma civilização diferente, não oposta a outras da Ásia ou da África. Nem os aspectos unificados do assim chamado "Império Romano", da "Época Helenística" ou do "Mundo Cristão", nem as guerras, foram capazes de cancelar as especificidades culturais. Por séculos, as guerras não tiveram relação com o tipo de guerra surgida após o século XVI.

O conceito de Ocidente como oposto a Oriente é relativamente novo, ligado a dois momentos que devem ser entendidos à luz de um terceiro momento (sobre o qual ainda não fomos bem esclarecidos). Primeiro: a conquista do oceano e o nascimento dos impérios marítimos de Portugal, Inglaterra, Espanha, Holanda, Suécia e Dinamarca; segundo: o nascimento dos Estados Unidos da América, que se tornou, depois da Doutrina de Monroe (1802), "A nação perigosa"; e a consolidação do maior império marítimo do mundo: os ingleses.

A conquista dos mares é ligada:

- à conquista das Américas;

- à introdução da pólvora, que mudou o jeito de guerrear (como ficou evidente na invasão da Itália em 1494 pelo exército de Carlos VIII - M. Boot, 2006);

- às decisões de dois países orientais: China (destruindo a frota de navios) e Japão (proibindo o uso de armas de fogo);

- à Reforma Protestante;

- à consolidação do comércio internacional;

- ao nascimento da nova modernidade, do novo capitalismo e da revolução industrial.
5. BRAGUE, Rémi. Eccentric Culture. A Theory of Western Civilization [Cultura excêntrica. Uma teoria da civilização ocidental]. Yale: St. Augustine's Press, 2002.

6. SCHMITT, Carl. II Nomos della terra [O Nomos da terra]. Milão: Adelphi, 2003.

7. KAGAN, Robert. Dangerous Nation. America and the World 1600-1898 [Nação perigosa. A América e o mundo 1600 1898]. New York: Atlantic Books, 2006. 
comunicação \& educação • Ano XVII • número 1 • jan/jun 2012

É durante esse período (séculos XVI ao XX) que uma nova ideologia foi criada com as contribuições de Maquiavel, Hobbes e Espinosa. Um novo mundo foi erigido, chamado de modernidade. O Ocidente tornou-se berço dos novos tempos, e a guerra, conflito entre religiões e ideologias. O Estado Nacional passou a instituição criadora de leis e justiça (cuius Regio eius Religio). As relações ancestrais, os deuses ligados à natureza, todas as tradições antigas foram considerados contra o Estado.

O triunfo da modernidade veio no século XIX: Estado Nacional, Colonialismo, Ciência e Progresso, Positivismo, Ocidente são as palavras-chave da nova era. Ninguém queria ouvir os pouquíssimos conscientes do que iria acontecer ao longo do século XX. As "guerras de extermínio" nas colônias e as "guerras de religião" na Europa (séculos XVI e XVII) tornaram-se a mais cruel forma de guerra: ideológica e nacionalista.

A conquista do "Novo Mundo", o nascimento dos impérios marítimos, o fechamento dos impérios asiáticos da China e Japão e a abertura da Rússia ocidental foram eventos que contribuíram para reduzir as funções estratégicas do Mundo Mediterrâneo de Cidades (como Gênova e Veneza, Roma e Barcelona) e Impérios (como o Islâmico e o Turco). Mas o século XX trouxe ainda um fenômeno inédito: as guerras civis.

Uma "guerra civil europeia" foi a assim chamada "Primeira Grande Guerra (1914-1918)". Uma "guerra civil russa" foi a assim chamada "Revolução Russa (1917-1922)". As duas contribuíram para a ascensão do Fascismo na Itália (1922) e do Nacional-Socialismo na Alemanha (1933), assim como para a "guerra civil” na Espanha (1936-1939) e a guerra sino-japonesa (1937-38) que levaram o mundo à Segunda Guerra Mundial (1939-1945) - tanto uma continuação da "guerra civil europeia" como uma guerra entre os dois maiores impérios marítimos (Estados Unidos e Japão).

No pós-guerra, começa o processo que leva ao terceiro momento decisivo da história mundial. Apenas duas potências chegaram ao fim da guerra com recursos econômicos, tecnológicos e políticos para desempenhar um papel imperial: os Estados Unidos, que permaneceram o único império marítimo, e a União Soviética, o mais importante império continental sem rivais - ambos prontos a tornarem-se líderes de coalizões com duas armas à sua disposição: as bombas nucleares e dois tipos diferentes de propaganda. Os meios de comunicação de massa e a fábrica de sonhos de Hollywood, de um lado; a utopia da sociedade comunista e as imagens de paz vindas de artistas e intelectuais antifascistas europeus e do Terceiro Mundo, de outro.

A ideia de "guerra fria" foi, principalmente, uma construção social de propaganda da oposição, escondendo o fato de que vivíamos, na realidade, a continuação de uma guerra civil. Nas guerras civis, os participantes não se consideram inimigos por lutarem por algo que não têm (isto é, território) e o inimigo tem; mas sim porque são "bons", enquanto os outros são "maus" ("razão", "Deus", "civilização" estão conosco e não com os "bárbaros", "criminosos"). O objetivo é não somente vencer o inimigo, mas eliminá-lo. 
Contando e compartilhando narrativas acadêmicas - Giovanni Bechelloni

Assim, o que aconteceu na "guerra fria" (1948-1989) não foi ainda falado abertamente, com a consequência de que muitas pessoas formaram ideias equivocadas daqueles anos. Uma delas é o conceito de civilização ocidental, reforçado com conteúdos ideológicos e culturais. Essa ideia é principalmente "norte-americana", construída com base num conceito prévio "anglo-saxão". No conceito de civilização ocidental não há muito do que foi europeu ou mediterrâneo antes do século XVI, ou do que foi europeu no pensamento dos fundadores na unificação da Europa antes, durante e depois das guerras civis europeias.

\section{CONSIDERAÇÕES FINAIS}

Em razão dos novos processos daqueles anos, chegamos a um momento decisivo. A invenção de novas armas, a revolução tecnológica ligada à informática e a construção de máquinas voadoras mudaram as relações entre territórios. A ideia de globalização é um conceito pobre para o que aconteceu: encaramos um novo estágio na existência histórica. $\mathrm{O}$ mar perdeu a importância central e, como consequência, o único império do mar, os Estados Unidos, é menos importante do que costumava ser.

O ar-condicionado e o novo tratamento da água são outras invenções que mudaram a importância de desertos territoriais localizados em áreas demasiadamente quentes. Pessoas e coisas se deslocam mais rapidamente e menos dispendiosamente. A territorialidade está de volta e pode dar novos sentidos de pertencimento às pessoas. Essa importante razão dá relevância estratégica aos territórios antes marginais. Por último, mas não menos importante, outros territórios repentinamente se tornaram importantes por conta do gás e do petróleo - que são a energia para os ativos do mundo moderno.

O que interessa neste momento é que não há apenas uma ou poucas superpotências capazes de liderar o mundo. Nem é possível conceber o colapso do comunismo soviético (1989-1991) como uma vitória do Ocidente e o fim da história. Ao contrário, vemos uma multipolaridade crescente. O que falta é consciência e energia para tomar a frente de um novo enredo. A má comunicação tem sido até agora o mau professor que diz a todos para viver no presente esquecendo o passado: um modo de evitar o aprendizado de caminhos para um futuro melhor.

\section{O LEGADO DE MAQUIAVEL}

Posso indicar os títulos de parágrafos a serem escritos:

- Precisamos pensar nos mais importantes mestres da Boa Comunicação: Sócrates, Jesus, Maquiavel.

- Precisamos celebrar como heróis os dois juízes sicilianos Falcone e Borsellino, mortos pela máfia ${ }^{8}$.

- Precisamos de humanos respeitáveis e responsáveis como cidadãos virtuosos.

- A virtude cívica republicana é mais forte que a lei.
8. BECHELLONI, Giovanni. I nostri eroi. La funzione bardica della televisione [Os nossos heróis. A função bárdica da televisão]. Napoli: Liguori, 2010. 


$$
\text { comunicação \& educação • Ano XVII • número } 1 \text { • jan/jun } 2012
$$

O que busco descobrir, através da análise geossociológica, pode ser um pensamento utópico. Porém, para chegar a novos lugares, é preciso cultivar uma nova visão. A visão que cultivo, embora guarnecida com esperança, é sedimentada pela análise. "Abrir a mente mediterrânea" não é algo já entre nós, mas pode ser, se nos atentarmos aos processos que pedem ser precondições para isso.

\section{REFERÊNCIAS BIBLIOGRÁFICAS}

ACKERMAN, Bruce. Before the Next Attack. Preserving Civil Liberties in the Age of Terrorism [Antes do próximo ataque. Preservando as liberdades civis na era do terrorismo]. Londres: Yale University Press, 2006.

AGAMBEN, G. Signatura Rerum [A marca das coisas]. Torino: Bollati-Boringhieri, 2008.

AL-FARABI. L'armonia delle opinioni dei due sapienti: il divino Platone e Aristotele [A harmonia das opiniões de dois sábios: o divino Platão e Aristóteles]. Pisa: Plus, Pisa University Press, 2008.

ANTOINE, Agnès. L'impensé de la démocratie: Tocqueville, la citoyenneté et la religion [O impensado da Democracia: Tocqueville, a cidadania e a religião]. Paris: Fayard, 2003.

APPIAH, Kwame Anthony. Cosmopolitanism Ethics in a World of Strangers [Cosmopolitismo. Ética num mundo de desconhecidos]. New York: Norton, 2006.

AL-NAYHUM, Al-Sadiq. Dalla Mecca a qui [De Meca até aqui]. Roma: Le Nuove Muse, 2007.

ARENDT, Hannah. La vita della mente [A vida da mente]. Bologna: Il Mulino, 2009.

ARLACCHI, Pino. L'inganno e la paura [A decepção e o medo]. Milano: Il Saggiatore, 2009.

BASSETTI, Piero. Italici. Il possibile futuro di una community globale [Itálicos. O possível futuro de uma comunidade global]. Lugano: Casagrande, 2008.

et al. Globus et Locus. Dieci anni di idee e pratiche 1998-2008 [Globus et Locus: dez anos de ideias e práticas]. Lugano: Casagrande, 2008.

BECHELLONI, Giovanni. Diventare cittadini del mondo [Tornar-se cidadão do mundo]. Roma-Firenze: Mediascape, 2006.

. Svolta comunicativa. Dieci lezioni. [Vez comunicativa. Dez lições]. RomaNapoli: Ipermedium Libri, 2007.

Communication for What [Comunicação para quê?]. São Paulo: ECAUSP, 2008.

. The Opening of Mediterranean Minds. Towards a Geo-sociological Approach to Mediterranean Studies [A abertura da mente mediterrânea. Em 
direção a uma abordagem geossociológica para os estudos mediterrâneos]. Barcelona: Forum ISA, 2008.

BECHELLONI, Giovanni. Beyond Multiculturalism. Learning how to understand Mediterranean Ancient World as Open Societies [Além do multiculturalismo. Aprendendo como entender o mundo antigo mediterrâneo como sociedades abertas]. Lesbon: PSA Congress, 2008.

La conversione dello sguardo. Verso nuovi orizzonti epistemologici negli studi di comunicazione [A conversão do olhar. Rumo a novos horizontes epistemológicos nos estudos de comunicação]. Roma-Napoli: Ipermedium Libri, 2009.

La comunicazione giornalistica. Una centralità poco percepita [A comunicação jornalística. Uma centralidade pouco percebida]. Firenze: Le Lettere, 2009.

I nostri eroi. La funzione bardica della televisione [Os nossos heróis. A função bárdica da televisão]. Napoli: Liguori, 2010.

BECK, Ulrich. World at risk [Mundo em risco]. Cambridge: Polity, 2009.

BELLOW, Adam. In Praise of Nepotism [Em louvor do nepotismo]. New York: Doubleday, 2003.

BERLIN, Isaiah. Political Ideas in the Romantic Age [Ideias políticas na era romântica]. New York: Chatto and Windus, 2006.

BIANCHERI, Boris. Accordare il mondo. La diplomazia nell'età globale [Sintonizar o mundo. A diplomacia na era global]. Roma-Bari: Laterza, 1999.

BLOOM, Allan. The Closing of the American Mind [O fechamento da mente americana]. Chicago: Chicago University Press, 1985.

Love and Friendship [Amor e amizade]. Paris: P.U.F., 1993.

BOURDIEU, Pierre. Sociologie de l'Algerie [Sociologia da Argélia]. Paris: P.U.F., 2006.

Esquisses Algeriennes [Esboços da Argélia]. Paris: Seuil, 2008.

BOUTROS-GHALI, Boutros; PERES, Shimon. 60 ans de conflit israélo-arabe [60 anos de conflito árabe-israelense]. Paris: Complexe, 2006.

BRAGUE, Rémi. La Sagesse du monde. Histoire de l'expérience humaine de l'Univers [Sabedoria do mundo. História da experiência humana do universo]. Paris: Fayard, 1999.

Eccentric Culture. A Theory of Western Civilization [Cultura excêntrica. Uma teoria da civilização ocidental]. Yale: St. Augustine's Press, 2002.

BRAUDEL, Fernand. La Mediterraneé [O Mediterrâneo]. Paris: Flammarion, 1985. 
comunicação \& educação • Ano XVII • número 1 • jan/jun 2012

BURLEIGH, Michael. In nome di Dio. Religione, Politica e Totalitarismo da Hitler ad Al Qaeda [Em nome de Deus. Religião, política e totalitarismo de Hitler à Al Qaeda]. Milano: Rizzoli, 2007.

CAMUS, Albert. Mediterraneo e conoscenza [Mediterrâneo e conhecimento]. Roma-Napoli: Ipermedium Libri, 2003.

. Le premier homme [O primeiro homem]. Paris: Gallimard, 2005.

CARANDINI, Andrea. Roma. Il primo giorno [Roma: o primeiro dia]. RomaBari: Laterza, 2007.

. Sindrome occidentale. Conversazioni fra un archeologo e uno storico sull'origine a Roma del diritto, della politica e dello stato [Sindrome ocidental. Conversas entre um arqueólogo e um historiador sobre a origem romana do direito, da política e do Estado]. Genova: Il Melangolo, 2007.

. Archeologia classica. Vedere il tempo antico con gli occhi del 2000 [Arqueologia clássica. Ver o tempo antigo com os olhos de 2000]. Torino: Einaudi, 2008.

CASSANO, Franco. Il pensiero meridiano [O pensamento meridiano]. RomaBari: Laterza, 2007.

CASSANO, Franco; ZOLO, Danilo. L'alternativa mediterranea [A alternativa mediterrânea]. Milão: Feltrinelli, 2007.

CHENG, François. Cinq méditations sur la beauté [Cinco meditações sobre a beleza]. Paris: Albin Michel, 2006.

CHIN, Annping. The Authentic Confucius [O Confúcio autêntico]. New York: Scribner, 2007.

CONFUCIO. Breviário. Milão: Bompiani, 2003.

COTESTA, Vittorio. Sociologia del mondo globale [Sociologia do mundo global]. Roma-Bari: Laterza, 2004.

Sociologia dei conflitti etnici [Sociologia dos conflitos étnicos]. RomaBari: Laterza, 2009.

DAYAN, Daniel. La terreur spectacle. Terrorism et télévision [O espetáculo do terror. Terrorismo e televisão]. Londres: De Boeck, 2006.

DE BENOIST, Alain. La governance: storia e dottrina di un'idea liberticida [A governança: história e doutrina de uma ideia liberticida], in Trasgressioni 47, 2008.

2008.

. Il nemico principale [O meu inimigo principal], in Trasgressioni 47,

DELPECH, Thérèse. L'ensauvagement. Le retour de la barbarie au XXI siècle [A selvageria. O retorno da barbárie no século XXI]. Paris: Hachette, 2005. 
Contando e compartilhando narrativas acadêmicas - Giovanni Bechelloni

EISENSTADT, Shmuel Noah et al. Public Spheres and Collective Identities [Esferas públicas e identidades coletivas]. Londres: Transaction, 2001.

[ed.]. Multiple modernities [Múltiplas modernidades]. New Jersey: Transaction, 2002.

FERGUSON, Niall. XX Secolo. L'età della violenza. Una nuova interpretazione del Novecento [Século XX. A idade da violência. Uma nova interpretação do Novecento]. Milano: Mondatori, 2008.

FISK, Robert. The Age of the Warrior. The Great War of Civilisation [A era do guerreiro. A grande guerra da civilização]. New York: Nation Books, 2008.

GAONKAR, Dilip Parameshwar. Alternative Modernities [Modernidades alternativas]. Durham: Duke University Press, 2001.

GARRONI, Emilio. Immagine, Linguaggio, Figura [Imagem, linguagem, figura]. Roma-Bari: Laterza, 2007.

GERMANI, Gino. Saggi Sociologici [Ensaios sociológicos]. Napoli: Libreria L'Atenero di G. Pironti, 1991.

La renovacion intellectual de la sociologia [A revolução intelectual da sociologia]. Buenos Aires: Universidad Nacional de Quilmes, 2006.

GIRARD, René. Achever Clausewitz [Clausewitz completo]. Paris: Carnets Nord, 2008.

GOODY, Jack. O roubo da história: como os europeus se apropriaram das ideias e invenções do Oriente. São Paulo: Editora Contexto, 2008.

GRANET, Marcel. La pensée chinoise [O pensamento chinês]. Paris: Albin Michel, 1999.

GRESS, David. From PLATO to NATO. The idea of the West and its opponents [De Platão a NATO. A ideia de Ocidente e seus oponentes]. Glencoe: The Free Press, 1998.

GUARRACINO, Scipione. Mediterraneo. Immagini, storie e teorie da Omero a Braudel [Mediterrâneo: imagens, histórias e teorias de Homero a Braudel]. Milão: Mondadori, 2007.

HARRIS, Lee. Civilization and its Enemies. The Next Stage of History [Civilização e seus inimigos. O novo estágio da história]. Glencoe: Free Press, 2004.

HECLO, Hugh. On Thinking Institutionally [Sobre pensar institucionalmente]. New York: Paradigm Publishers, 2008.

HIMMELFARB, Gertrude. The Roads to Modernity [As estradas para a Modernidade]. New York: Vintage Books, 2004.

IBRAHIM, Raymond. The Al Quaeda Reader [O leitor da Al Quaeda]. New York: Broadway Books, 2007. 
comunicação \& educação • Ano XVII • número 1 • jan/jun 2012

JENKINS, Henr. Convergence Culture. Where Old and New Media Collide [A Cultura da Convergência. Onde velhas e novas mídias colidem]. New York: New York University Press, 2006.

JUDT, Tony. Reappraisals [Reavaliações]. New York: The Penguin Press HC, 2008.

JULLIEN, François. Sull'efficacia. Cina e Occidente a confronto [Sobre eficácia. China e Ocidente em comparação]. Milano: Il Sole 24 Ore, 2008.

KAGAN, Robert. Dangerous Nation. America and the World 1600-1898 [Nação Perigosa. A América e o mundo 1600-1898]. New York: Atlantic Books, 2006.

KHANNA, Parag. The Second World. Empires and influence in the new global order [O Segundo Mundo. Impérios e influência na nova ordem global]. New York: Randhom House, 2008.

LAFRANCE, Jean-Paul et al. Place et Role de la Communication dans le développement international [Lugar e papel da comunicação em Desenvolvimento Internacional]. Quebec: Presses de l'Université du Quebec, 2006.

LANE, Eric et ORESKES, Michael. Le Génie de l'Amérique [O gênio da América]. Paris: Odile Jacob, 2008.

LAQUEUR, Walter. The Last Days of Europe, Epitaph for an Old Continent [Os últimos dias da europa. Epitáfio para um velho continente]. New York: St. Martin's Press, 2007.

LATOUCHE, Serge. Petit traité de la décroissance serein [Pequeno tratado da decadência serena]. Paris: Fayard, 2007.

LEWIS, Bernard. From Babel to Dragomans [De Babel aos intérpretes]. Oxford: Oxford University Press, 2004.

LLOYD, Geoffrey. Grecia e Cina: due culture a confronto [Grécia e China: duas culturas em comparação]. Milão: Feltrinelli, 2008.

LULL, James. Culture-On-Demand. Communication in a Crisis World [Cultura sob demanda. A comunicação em um mundo em crise]. Londres: Balckwell, 2007.

MADDISON, Angus. Phases of Capitalist Developpment [Fases do desenvolvimento capitalista]. Oxford: Oxford University Press, 1982.

MANDEL, Gabriele. La via al sufismo [O caminho para o sufismo]. Milão: Bompiani, 2004.

MARTIN, Henry-Jean. Histoire et pouvoirs de l'écrit [História e poder da escrita]. Paris: Librairie Academique Perrin, 1988.

MATVEJEVIC, Predrag. Breviario mediterraneo [Breviário mediterrâneo]. Milano: Garzanti, 2009.

McCHESNEY, Robert. Communication revolution [A revolução da comunicação]. New York: The New Press, 2007. 
Contando e compartilhando narrativas acadêmicas - Giovanni Bechelloni

MUASHER, Marwan. The Arab Center [O centro árabe]. New Haven: Yale University Press, 2008.

MUMON. La porta senza porta [A porta sem porta]. Milão: Adelphi, 2006.

NEMO, Philippe. Que'est-ce que l'Occident? [O que é o ocidente?]. Paris: P.U.F., 2004.

PETERS, John Durham. Courting the Abyss. Free Speech and the Liberal Tradition [Cortejando o abismo. Liberdade de expressão e a tradição liberal]. Chicago: The University of Chicago Press, 2005.

PETRICIOLI, Marta. L'Europe méditerranéenne [A Europa mediterrânea]. Paris: P.D.E. Peter Lang, 2008.

PIETERSE, Jan Nederveen. Globalization and Gulture [Globalização e cultura]. New York: Rowman and Littlefield, 2004.

REID, Michael. Forgotten Continent. The Battle for Latin America's Soul [O continente esquecido. A batalha pela alma latino-americana]. New Haven: Yale University Press, 2007.

RICHARD, Marie-Dominique. L'insegnamento orale di Platone [O ensino oral de Platão]. Milano: Bompiani, 2008.

RUFFOLO, Giorgio. Quando l'Italia era una super-potenza [Quando a Itália era uma superpotência]. Torino: Einaudi, 2004.

Il capitalismo ha i secoli contati [O capitalismo tem os séculos contados]. Torino: Einaudi, 2008.

SALZMAN, Philip Carl. Culture and Conflict in the Middle East [Cultura e conflito no Oriente Médio]. New York: Humanity Books, 2008.

SASSOON, Donald. La cultura degli euorpei dal 1800 a oggi [A cultura dos europeus de 1800 a hoje]. Milão: Rizzoli, 2008.

SCHAUB, Jean-Frédéric. L'Europe a-t-elle une histoire? [A Europa tem uma história?]. Paris: Albin Michel, 2008.

SCHUDSON, Michael. Why democracies need an unlovable press [Por que as democracias precisam de uma imprensa desagradável]. Cambridge: Polity, 2008.

SEARLE, John. Occidente e multiculturalismo [Ocidente e multiculturalismo]. Milano: Il Sole 24 Ore, 2008.

SHARANSKY, Natan. The Case for Democracy [Em defesa da democracia]. New York: Pulic Affairs, 2006.

SCHMITT, Carl. Il Nomos della terra [O Nomos da terra]. Milano: Adelphi, 2003.

Il concetto discriminatorio di guerra [O conceito discriminatório de guerra]. Roma-Bari: Laterza, 2008.

SIVANANDA, Sri Swami. Thought Power [O poder do pensamento]. YogaVedanta Forest Academy, Divine Life Society, 1963. 
comunicação \& educação • Ano XVII • número 1 • jan/jun 2012

SLODERDIJK, Peter. Colère et temps [Cólera e os tempos]. Paris: Libella Maren Sell, 2007.

SNELL, Bruno. La decouverte de l'esprit. La genèse de la pensée européenne chez les Grecs [A descoberta da mente. A gênese do pensamento europeu desde os gregos]. Paris: Editions de l'Eclat, 1994.

SPITZER, Leo. L'armonia del mondo [A harmonia do mundo]. Bologna: Il Mulino, 2009.

STEINER, George. La barbarie dell'ignoranza [A barbárie da ignorância]. Napoli: Nottetempo, 2005.

TAYLOR, Charles. Sources of the Self [As fontes do self]. Cambridge: Harvand University Press, 1989.

2007.

. A Secular Age [Uma era secular]. Cambridge: Harvard University Press,

TOBINO, Mario. Il deserto della Libia [O deserto da Líbia]. Milano: Oscar Mondadori, 2001.

TOMLINSON, John. The Culture of Speed. The Coming of Immediacy [A cultura da velocidade. A vinda da imediatez]. Paris: Sage, 2007.

VALORI, Elia. Mediterraneo tra pace e terrorismo [Mediterrâneo entre a paz e o terrorismo]. Milão: Rizzoli, 2008.

VV.AA. L'età delle Nazioni [A idade das nações], Aspenia, 44, 2009.

La Cina spacca l'Occidente [A China divide o Ocidente]. Cadernos especiais de Limes, suplemento n. 4, 2009.

Esiste l'Italia? Dipende da noi [Existe Itália? Depende de nós], Limes n. 2, 2009.

Europe. Mémoires Profondes [Europa. Memórias profundas]. Paris: Autrement, 2008.

WEIGEL, George. Faith, Reason, and the War against Jihadism. A Call for Action [Fé, razão, e a guerra contra o Jihadismo. Uma chamada para a ação]. New York: Doubleday, 2007.

WILSON, Colin. The Outsider [O estrangeiro]. Londres: Pan Books, 1971.

WILSON, Emily. The Death of Socrates [A morte de Sócrates]. New York: Profile Books, 2007.

WOLTON, Dominique. L'autre mondialisation [Uma outra globalização]. Paris: Flammarion, 2003.

. Il faut sauver la communication [Nós temos que salvar a comunicação].

Paris: Flammarion, 2005. 